\title{
Structural and Optical Properties Investigation on H-Bonded 1D Helical Self- Assembly of 1,1-Dibenzyl-3-(2-Bromobenzoyl)thiourea Molecules for Nonlinear Optical Application
}

(Kajian Struktur dan Sifat Optik Himpunan Kendiri Molekul 1,1-Dibenzil-3-(2-Bromobenzoil)thiourea dengan Ikatan-H 1D untuk Aplikasi Optik tak Linear)

Wun Fui Mark-Lee, Mohd Faizal Md Nasir \& Mohammad B. KASSiM*

ABSTRACT

A benzoylthiourea molecule namely 1,1-dibenzyl-3-(2-bromobenzoyl)thiourea (2BrBT) was synthesized and characterized by $C, H, N$ and $S$ elemental, mass spectrometry and spectroscopic analyses (infrared, ultraviolet-visible and nuclear magnetic resonance). The $2 B r B T$ compound crystallized in a tetragonal system with the space group P $4_{3}$ and exhibits an acentric crystalline packing due to the presence of intermolecular H-bonding network that forms a self-assembly of $1 D$ helical motif. The asymmetric delocalisation of electrons in the molecule retains its transparency throughout the visible and near-infrared region and hence, essentially propagates the macroscopic helical motif in the solid state. The highest-occupied and lowest-unoccupied molecular orbital (HOMO/LUMO) are mainly found on the thiourea moiety and the benzoylthiourea fragment, respectively and shows an optical bandgap of $3.50 \mathrm{eV}$. The influence of its geometrical characteristics to the optical properties of $2 \mathrm{BrBT}$ is established and discussed in view of nonlinear optical (NLO) application.

Keywords: Benzoylthiourea; crystal structure; DFT; nonlinear optical material

ABSTRAK

Molekul benzoiltiourea terbitan 1,1-dibenzil-3-(2-bromobenzoil)tiourea (2BrBT) telah berjaya disintesis dan dicirikan menggunakan teknik analisis unsur $C, H, N$ dan $S$, spektrometri jisim dan spektroskopi (FT-IR, UV-Vis, ${ }^{1} H$ dan ${ }^{13} C$ NMR). Kompaun 2BrBT menghablur dalam sistem tetragonal dengan kumpulan ruang $\mathrm{P}_{3}$ dan menunjukkan padatan hablur yang bersifat asentrik akibat jaringan ikatan-H 1D. Jaringan akibat ikatan hidrogen intermolekul menyebabkan molekul 2BrBT tersusun secara kendiri untuk membentuk motifheliks satu dimensi dalam keadaan fasa pepejal. Penyahsetempatan elektron secara asimetrik di dalam molekul telah mengekalkan sifat lutsinar terhadap radiasi di seluruh kawasan cahaya nampak dan inframerah-dekat serta menggalakkan pembentukan motif makroskopik heliks dalam keadaan pepejal. Pengaruh geometri terhadap sifat optik molekul 2BrBT dibincang dan dihubungkaitkan terhadap aplikasi optik tak linear (NLO).

Kata kunci: Bahan optik tak linear; benzoil tiourea; struktur kristal; teori fungsi ketumpatan (DFT)

\section{INTRODUCTION}

In recent years, the research on non-linear optical materials has propelled numerous efforts to develop novel material with a second order optical non-linearity (Anbarasi et al. 2017; Balaji et al. 2016; Purusothaman et al. 2015; Shahriari et al. 2011). Non-linear organic (NLO) materials exhibit acentric hyperpolarizability induced by external electric fields of the light (Irudaya Jothi \& Alexander 2017). The increase in the first order hyperpolarizability can be realised with the implementation of stronger electron donating and accepting substituents at the molecule level and extension of $\pi$-conjugation linkages (Bosshard et al. 2000; Dalton et al. 2015). However, the presence of these strong donor and acceptor substituents on the molecule tends to promote a centrosymmetric construction of the crystal macrostructure
(Lee et al. 2016). The onus lies on introducing molecular adducts with non-centrosymmetrical core which can successively assemble into an acentric crystal structure. Besides, the versatility of molecular modification, waterfree crystal formation, visible and near-infrared light transparency should also be considered. Moreover, the evaluation of organic molecules regarding their intrinsic optical and structural properties is consequential for its use as NLO materials for various photonic applications (Jazbinsek et al. 2008; Shi et al. 2015).

A dibenzylamine unit is connected to the benzoylthiourea moiety to form the titled compound (Nasir et al. 2011). The introduction of three pendant phenyl rings by default may stimulate steric hindrance which advocates the development of acentric crystal motifs. 2BrBT contains strong donor groups i.e. carbonyl 
and thioamide, which is also the characteristic feature of benzoylthiourea derivatives (Ngah et al. 2006a, 2006b). The self-assembly of $2 \mathrm{BrBT}$ units depends on these strong electron donors to form a non-covalent macrostructure network through intermolecular hydrogen bonding. The ortho-Br substituent of the benzoyl moiety essentially induces structural distortion due to steric repulsion; while, it may complement the stability and asymmetric $\pi$-conjugation of its supramolecular structure via intramolecular hydrogen bonding. Herein, the synthesis and characterisation of a benzoylthiourea molecule are discussed with an emphasis on the structural and optical features for NLO consideration.

\section{EXPERIMENTAL DETAILS}

\section{PHYSICAL MEASUREMENTS}

All reactions were performed under an ambient atmosphere and no special procedures were required to contain air or moisture contact. Chemicals and solvents were purchased from Sigma Aldrich and Merck and used as received without further purification. Infrared spectra were obtained using an ATR-FTIR Spectrophotometer in the spectral range of $4000-400 \mathrm{~cm}^{-1}$. The ${ }^{1} \mathrm{H}$ and ${ }^{13} \mathrm{C}$ NMR spectra were recorded in a DMSO- $\mathrm{d}_{6}$ solvent using a Bruker 600 Spectrometer at room temperature. The elemental analyses were conducted using CHNS Analyzer Flash EA 1112 series. Single crystal X-ray data were collected on Bruker SMART APEX CCD area detector diffractometer and the solution was obtained by using SHELXTL programme suite. The mass spectrum of the sample was collected by Shimadzu QP5050A/QP2010 PLUS spectrometer.

\section{SYNTHESIS OF 1,1-DIBENZYL-3-(2-BROMOBENZOYL) THIOUREA}

The titled compound was synthesized according to previous reports (Hassan et al. 2008; Nasir et al. 2011). An acetone $(30 \mathrm{~mL})$ solution of 2-bromobenzoyl chloride (10 mmol) was added dropwise to a suspension of potassium thiocyanate $(10 \mathrm{mmol})$ in acetone $(30 \mathrm{~mL})$ and the reaction mixture was heated to a refluxing temperature for $30 \mathrm{~min}$. Then a solution of the dibenzylamine $(10 \mathrm{mmol})$ dissolved in acetone $(10 \mathrm{~mL})$ was added to the reaction mixture and heated for another ca. 2-3 h. Finally, the reaction mixture was poured into a cold water and to give a precipitate, filtered and washed with cold water. The product was recrystallized from aqueous methanol/chloroform to give the desired compound (yield $=75 \%$ ).

\section{COMPUTATIONAL METHODS}

The atomic coordinates for the structure of the $2 \mathrm{BrBT}$ were obtained from the single crystal X-ray diffraction data (Nasir et al. 2011). The geometry and electronic structure of the molecule were subsequently optimised with Gaussian 09 software based on $a b$ initio method of density functional theory (DFT) and time-dependent (TD) DFT, respectively. The Lee-Yang-Parr (B3LYP) exchange- correlation functional was used for the theoretical approach employing the $6-311++\mathrm{G}(\mathrm{d}, \mathrm{p})$ basis-set with polarization and diffuse functions for $\mathrm{H}, \mathrm{C}, \mathrm{N}, \mathrm{O}, \mathrm{S}$ and $\mathrm{Br}$ atoms (Becke 1993, 1988; Davidson \& Feller 1986; Hehre et al. 1986; Lee et al. 1988). The vibrational frequency calculations were performed and checked to obtain only positive eigen values. The solvent reaction field for ethanol ( $\mathrm{e}=$ 24.852) was considered for the geometry optimisation with Tomasi's polarizable continuum model (PCM) (Cossi et al. 2003; Miertuš et al. 1981).

\section{RESULTS AND DISCUSSION}

\section{CHEMICAL AND SPECTROSCOPIC ANALYSIS}

The result of the micro elemental analysis for $\mathrm{C}, \mathrm{H}, \mathrm{N}$ and $\mathrm{S}$ of $2 \mathrm{BrBT}$ agreed with the theoretical calculation values based on the empirical formula of $\mathrm{C}_{22} \mathrm{H}_{19} \mathrm{BrN}_{2} \mathrm{OS}$ (calculated (found): $\mathrm{C}=60.00$ (60.44), $\mathrm{H}=4.58$ (4.17), $\mathrm{N}=6.36(6.47)$ and $\mathrm{S}=7.28(7.94))$. The mass to charge ratio $(\mathrm{m} / \mathrm{z}$ ) of $2 \mathrm{BrBT}$ was 440.20 (calc. $\mathrm{m} / \mathrm{z}=440.04$ ) for the positively charged $(2 \mathrm{BrBT})^{+}$molecular ion.

2BrBT exhibits four significant stretching vibration frequencies namely, $v(\mathrm{~N}-\mathrm{H})=3216, v(\mathrm{C}=\mathrm{O})=1672$, $v(\mathrm{C}-\mathrm{N})=1525$ and $v(\mathrm{C}=\mathrm{S})=1249 \mathrm{~cm}^{-1}$. The ${ }^{1} \mathrm{H}-\mathrm{NMR}$ spectrum showed signals at $4.67 \& 5.23,7.17-7.79$ and $11.04 \mathrm{ppm}$, which were assigned to the methylene $\left(-\mathrm{CH}_{2}\right)$, phenyl and $\mathrm{N}-\mathrm{H}$ protons, respectively. The protons in the phenyl were difficult to assign due to the overlapping of signals with chemically equivalent environments for the protons from three benzene rings of benzo-carbonyl and benzo-thioamide moieties. Meanwhile, the ${ }^{13} \mathrm{C}$-NMR recorded signals at $56.14 \& 55.20,128.23-132.39,164.18$ and $183.61 \mathrm{ppm}$ for methylene, benzene, $\mathrm{C}=\mathrm{O}$ (benzamide) and $\mathrm{C}=\mathrm{S}$ (thioamide), respectively.

\section{CRYSTAL STRUCTURE DETERMINATION}

The single crystal X-ray diffraction data; selected bond lengths and angles of the $2 \mathrm{BrBT}$ structure are listed in Tables 1 and 2, respectively (Nasir et al. 2011). The noncentrosymmetric crystalline packing is verified by its space group, $\mathrm{P}_{3}$, which is the prerequisite of an organic compound to exhibit second-order nonlinear optical properties (Lee et al. 2016). The molecular structure of 2BrBT is depicted in Figure 1. The bromobenzoyl moiety is essentially planar with a torsion angle of $130.70^{\circ}$ (C5/C6/C7/O1). This distortion is likely due to the force created by the density of the electron on neighbouring atoms in close proximity that repelled each other. Congruently, the phenyl moiety adopts a trans configuration with regard to the thiono $\mathrm{S}$ atom along the N1-C8 bond.

The phenyl rings of dibenzylamine moiety are twisted with respect to each other and adopted a cis and trans configuration with respect to the thiono $\mathrm{S}$ atom at the N2$\mathrm{C} 8$ bond. A weak intramolecular hydrogen bond, N1-H5 ... $\mathrm{Br} 1$ led to the construction of a pseudo-six-membered ring (N1/H5/Br1/C5/C6/C7). Concurrently, an intermolecular hydrogen bonding was also observed in the crystal lattice, 
TABLE 1. Crystal data and structure refinement parameters for 2BrBT

\begin{tabular}{lc}
\hline Parameter & Data \\
\hline Empirical formula & $\mathrm{C}_{22} \mathrm{H}_{19} \mathrm{BrN}_{2} \mathrm{OS}$ \\
Formula weight & 439.36 \\
Temperature/K & $546(2)$ \\
Crystal system & tetragonal \\
Space group & $\mathrm{P} 4{ }_{3}$ \\
$\mathrm{a} / \AA$ & $12.2833(16)$ \\
$\mathrm{b} / \AA$ & $12.2833(16)$ \\
$\mathrm{c} / \AA$ & $14.002(4)$ \\
$\alpha /{ }^{\circ} \& \beta /{ }^{\circ}$ & 90.00 \\
Volume $/ \AA^{3}$ & $2112.6(7)$ \\
$\mathrm{Z}$ & 4 \\
Crystal size $/ \mathrm{mm}^{3}$ & $0.35 \times 0.31 \times 0.23$ \\
$2 \Theta$ range for data collection & 3.32 to $56.7^{\circ}$ \\
\hline
\end{tabular}

TABLE 2. Geometric parameters of selected bond lengths $(\AA)$ and angles $\left(^{\circ}\right)$ for $2 \mathrm{BrBT}$

\begin{tabular}{llll}
\hline Bond & length $(\AA)$ & Angle & Degree $\left({ }^{\circ}\right)$ \\
\hline S1-C8 & $1.666(4)$ & O1-C7-N1 & $122.9(3)$ \\
O1-C7 & $1.203(4)$ & N1-C8-S1 & $117.4(3)$ \\
N1-C7 & $1.356(5)$ & N2-C8-S1 & $117.4(3)$ \\
N1-C8 & $1.396(5)$ & C8-N2-C9 & $124.3(3)$ \\
N2-C8 & $1.330(5)$ & & \\
Br1-C1 & $1.909(4)$ & & \\
\hline
\end{tabular}

N1-H5 $\cdots$ O1' connecting adjacent 2BrBT molecules into a $1 \mathrm{D}$ network as discussed in the next section.

\section{ELECTRONIC STRUCTURE AND ABSORPTION PROPERTIES}

Based on the Mulliken population analysis, the two highest atomic charges obtained from DFT calculation belongs to $\mathrm{O} 1$ and $\mathrm{N} 1$ atoms and the highest positive charge site is found on the $\mathrm{H} 5$ and $\mathrm{C} 7$ atoms which are bonded to $\mathrm{N} 1$ and O1, respectively (Figure 2). Besides, the presence of negative and positive charges are an indication of their electron donating and accepting abilities. Comparatively, $\mathrm{H} 5$ has a lower positive charge than $\mathrm{C} 7$ due to the presence of two hydrogen bondings connecting H5. The calculated Mulliken charge distribution data indicates a significant fluctuation of charges predominantly located on the bridging backbone connecting the three pendant phenyl rings of the molecule.

The pseudo-six-membered ring (N1/H5/Br1/C5/ $\mathrm{C} 6 / \mathrm{C} 7)$ formed by the intramolecular hydrogen bonding enhanced the electron delocalisation via the conjugated pathway resulted from the interaction, which also stabilizes the asymmetric polarisation across the molecule. The trans conformation of $\mathrm{H}$ and $\mathrm{O}$ atoms of the amide group of benzoylthiourea fragment enabled the zig-zag intermolecular hydrogen bonding with neighbouring molecules that facilitated the self-assembly of an infinite 1D structure along the $C$-axis (Figure 3(a)). The versatile benzoylthiourea aliphatic fragment supports the delocalisation of electrons to form a resonance structure that is able to accommodate the donation of lone pair (electrons) for hydrogen bond formation (Figure 4(b)).

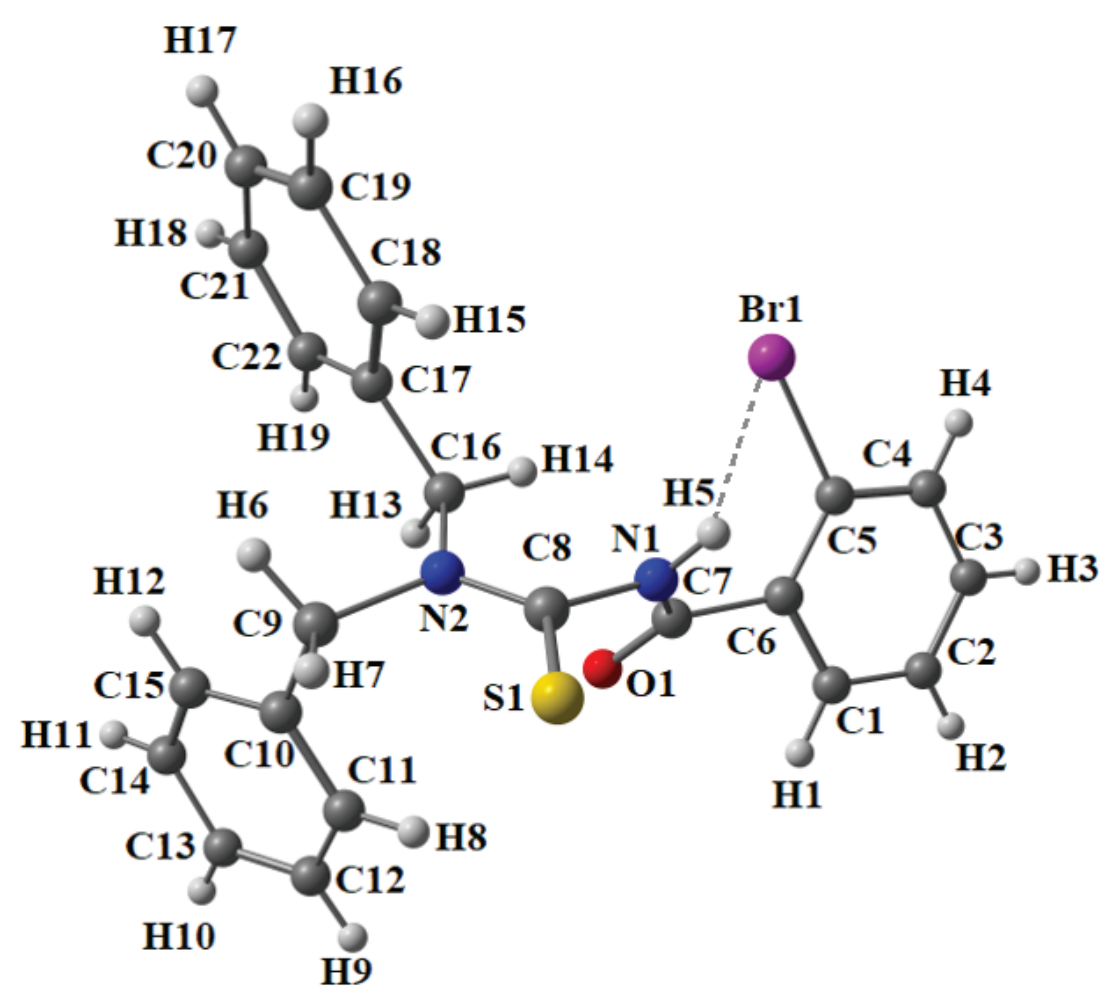

FIGURE 1. The structural diagram of 1,1-dibenzyl-3-(2-bromobenzoyl)thiourea according to the coordinates obtained from x-ray single-crystal diffraction 


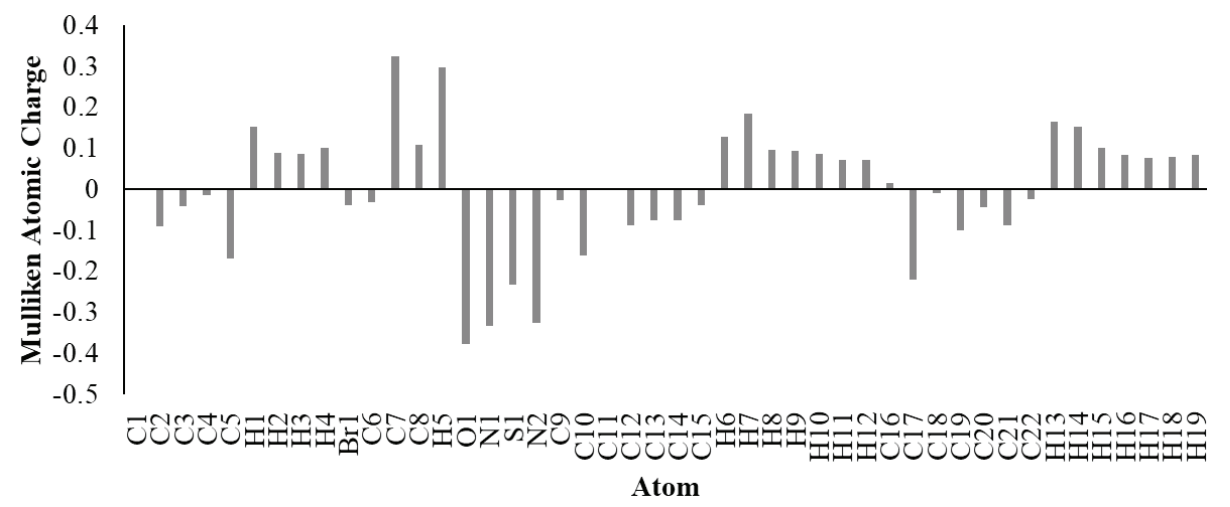

FIGURE 2. The distribution of Mulliken atomic charges of the optimised 2BrBT structure with atomic numbering order according to Figure 1
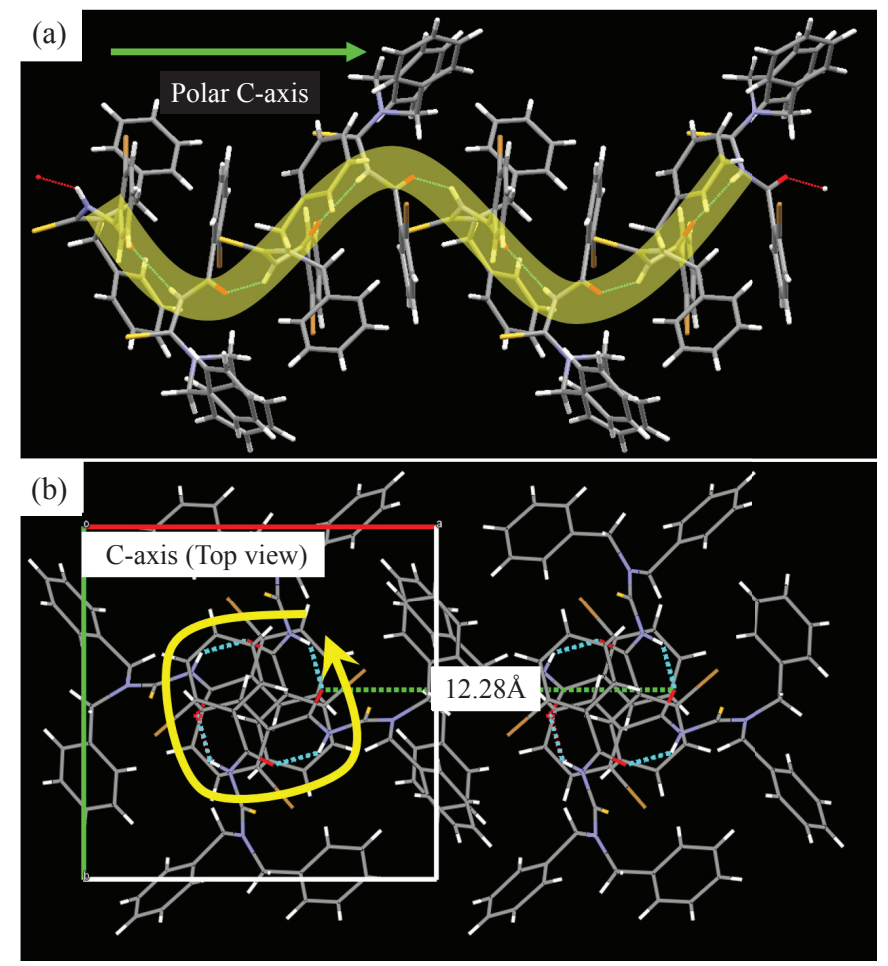

FIGURE 3. Packing diagram of (a) 2BrBT from the side-view (B-axis): Zig-zag chain of intermolecular H-bond along C-axis; and (b) top-view of C-axis: square-cylindrical spiral column established by the intermolecular H-bond represented by blue dotted lines

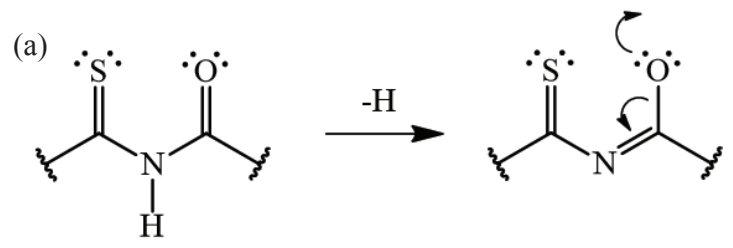

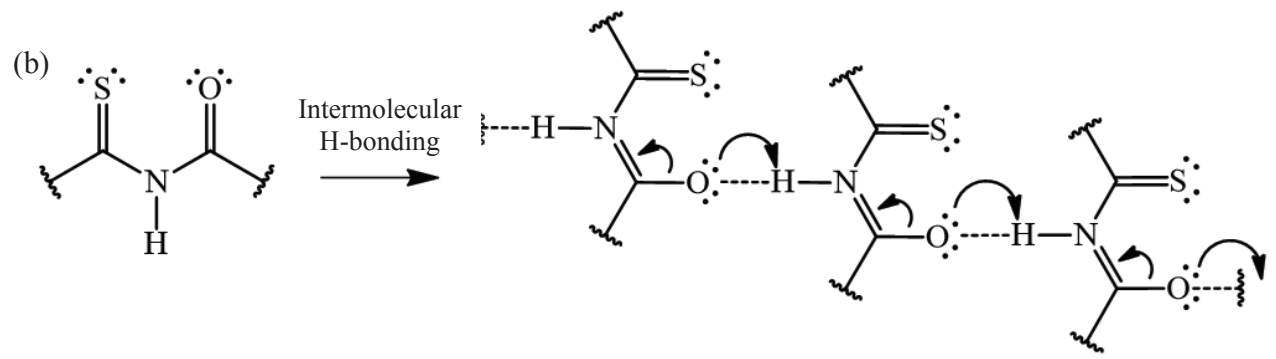

FIGURE 4. Electron flow involved in the (a) elimination of $\mathrm{H}$ atom of amine and (b) intermolecular hydrogen bonding of benzoylthiourea aliphatic linkage 
Similar molecules were also known to act as a cisbidentate ligand ( $\mathrm{S}$ and $\mathrm{O}$ donor atoms) for organometallic complexation via the elimination of hydrogen atom from the secondary amine (Figure 4(a)). This configuration contributes to an effective uninegative charge to the respective coordinated complex (Tan et al. 2014). The helix structure forms a square-cylindrical spiral column as observed from the top view of $\mathrm{C}$-axis (Figure $3(\mathrm{~b})$ ). The molecules are separated from each other by a distance of $12.28 \AA$; measured from $\mathrm{O} 1$ of a molecule to $\mathrm{O} 1$ ' of the neighbouring molecule.

TDDFT calculation was performed on the optimised $2 \mathrm{BrBT}$ structure with the consideration of solvent (ethanol) reaction field. One hundred vertical excited states were taken into account for the calculation. The resulting vertical excited states were interpolated into a curve (Gaussian distribution) to simulate the experimental absorption spectrum shown in Figure 5. The calculated absorption spectrum demonstrated three dominant bands and they resemble the profile of the experimental spectrum and shows the same number of bands and relative peak intensities. The three absorption bands are labelled as I, II and III. Relatively, the calculated absorption bands are slightly red-shifted (bathochromic) with respect to the experimental absorption bands. It is known that calculations based on the hybrid function (B3LYP) tend to over-estimate the optical energies compared to experimental results (Fui et al. 2016; Mark-Lee et al. 2017).

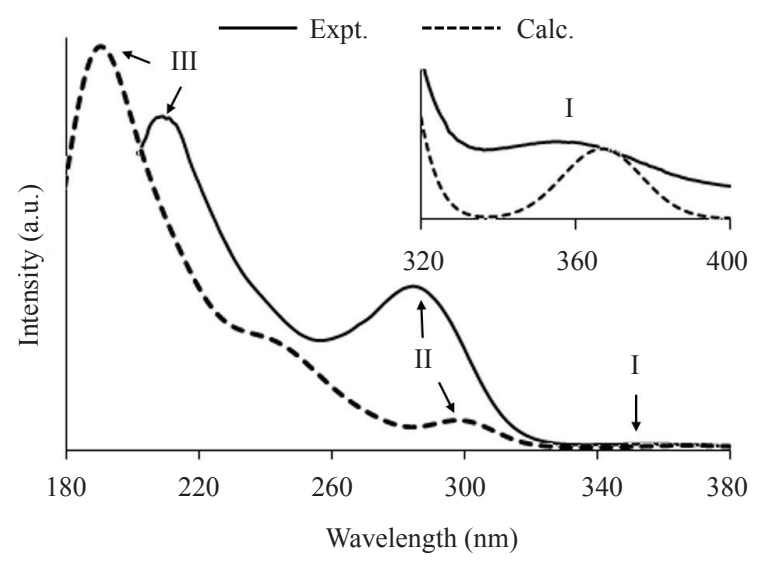

FIGURE 5. Comparison of the experimental (solid line) and calculated (dashed line) UV-Vis absorption spectra of 2BrBT in ethanol. Inset: the close-in image of the curve at 320-400 nm
Both experimental and calculated electronic absorption data: maximum wavelength $\left(1_{\max }\right)$, optical bandgap $\left(E_{\mathrm{g}}\right)$, extinction coefficient $(\varepsilon)$, oscillator strengths $(f)$, predominant transitions and orbitals involved, are tabulated in Table 3. Figure 6 illustrates the four frontier molecular orbitals of 2BrBT. The initial electronic excitation (band I) with a very low extinction coefficient was found at $1_{\max }=354 \mathrm{~nm} ; \varepsilon=0.032 \times 10^{4} \mathrm{M}^{-1} \mathrm{~cm}^{-1}$ (calc: $367 \mathrm{~nm}$; $f=0.0095)$. This electronic transition was predicted to involve the frontier molecular orbitals, HOMO ${ }^{\circledR}$ LUMO with an optical bandgap $=3.50 \mathrm{eV}$. The HOMO is predominantly located on the thiourea fragment with a higher saturation of electrons found on the $\mathrm{S}$ atom of the thiocarbonyl moiety and it will be a focal point for further discussion. While the LUMO is spread across the benzoylthiourea moiety. The low extinction coefficient of the electronic excitation can be explained from the viewpoint of $\mathrm{S}$ atom. The photoinduced excitation of electrons from the filled $p_{\mathrm{x}}$-orbital (S atom) essentially populates the empty molecular orbitals (LUMO), which consists of $s$ and $p_{\mathrm{y}}$ orbitals. Orbital with different orientations involved in the HOMO ${ }^{\circledR}$ LUMO transition may hinder the efficiency of electronic transfer.

The next higher energy transition (Band II) was recorded in the $250-320 \mathrm{~nm}$ region, $1_{\max }=284 \mathrm{~nm}$ with a higher peak intensity $\left(\varepsilon=1.065 \times 10^{4} \mathrm{M}^{-1} \mathrm{~cm}^{-1}\right)$. This electronic transition is ascribed to the HOMO- $1 \rightarrow$ LUMO with a percentage contribution of $92 \%$. The higher participation of electrons in the electronic excitation is comprehensible as per argument focusing on the $\mathrm{S}$ atom. Now, the lower lying HOMO-1 involves the $p_{\mathrm{y}}$ orbitals which are more favourable to populate the empty LUMO. A shoulder absorption peak was present in the calculated spectrum (220-260 nm). Likewise, the experimental spectrum also showed an essential overlap of bands in the same region. A prominent electronic excitation was identified to be involved in the absorption band (III). The photoexcited electrons originate from the occupied molecular orbitals of HOMO-2 to the higher lying LUMO +10 .

These results showed that the skeletal structure of 2BrBT paves the way for the asymmetric delocalisation of $\pi$-conjugated electrons across the molecule and suggest that the macroscopic delocalisation of non-bonded electrons are established in the solid-state (crystal) by the intermolecular hydrogen bonding. The asymmetric delocalisation of photoexcited electrons in the macrostructure crystalline framework may translate to an appreciable dipole-

TABLE 3. Experimental and calculated UV-Vis absorption data for 2BrBT measured in ethanol

\begin{tabular}{|c|c|c|c|c|c|c|c|}
\hline & \multicolumn{3}{|c|}{ Expt. } & \multicolumn{3}{|c|}{$\begin{array}{l}\text { TDDFT/ } \\
\text { B3LYP }\end{array}$} & \multirow[t]{2}{*}{ Key transitions and characters ${ }^{\mathrm{c}}$} \\
\hline & $1_{\max }$ & $E_{\mathrm{g}}{ }^{\mathrm{a}}$ & $e^{\mathrm{b}}$ & $1_{\max }$ & $E_{\mathrm{g}}^{\mathrm{a}}$ & Osc. ${ }^{b}$ & \\
\hline & $(\mathrm{nm})$ & $(\mathrm{eV})$ & & $(\mathrm{nm})$ & $(\mathrm{eV})$ & $(f)$ & \\
\hline I & 354 & 3.50 & 0.032 & 367 & 3.38 & 0.0095 & $(85 \%) \mathrm{HOMO}_{(\mathrm{t}+c \text {-ph })} \rightarrow \mathrm{LUMO}_{(\mathrm{bt})}$ \\
\hline II & 284 & 4.36 & 1.065 & 299 & 4.15 & 0.1225 & $(92 \%) \mathrm{HOMO}_{(\mathrm{t}+t-\mathrm{ph})} \rightarrow \mathrm{LUMO}_{(\mathrm{bt})}$ \\
\hline III & 209 & 5.93 & 2.180 & 188 & 5.14 & 0.2982 & $\left.(21 \%) \mathrm{HOMO}-2_{\left(\mathrm{t}+{ }^{*}\right.} c_{\text {-ph }}\right)^{\circledR} \mathrm{LUMO}+10_{(\mathrm{bt})}$ \\
\hline
\end{tabular}

${ }^{\mathrm{a}} E_{\mathrm{g}}=1239.5 / 1_{\max }$ (Fui et al. 2012; Mark-Lee et al. 2013)

${ }^{\mathrm{b}} 1_{\max } / \mathrm{nm},\left(e\left({ }^{\prime} 10^{4} \mathrm{M}^{-1} \mathrm{~cm}^{-1}\right)\right) ; 1.0^{\prime} 10^{-4} \mathrm{M}$; Osc. = Oscillator strength

${ }^{\mathrm{c}} \mathrm{t}=$ thiourea; $\mathrm{bt}=$ benzoylthiourea, $c / t$-ph $=$ cis/trans-phenyl (with respect to thiocarbonyl), $*$ with higher electron population involved 


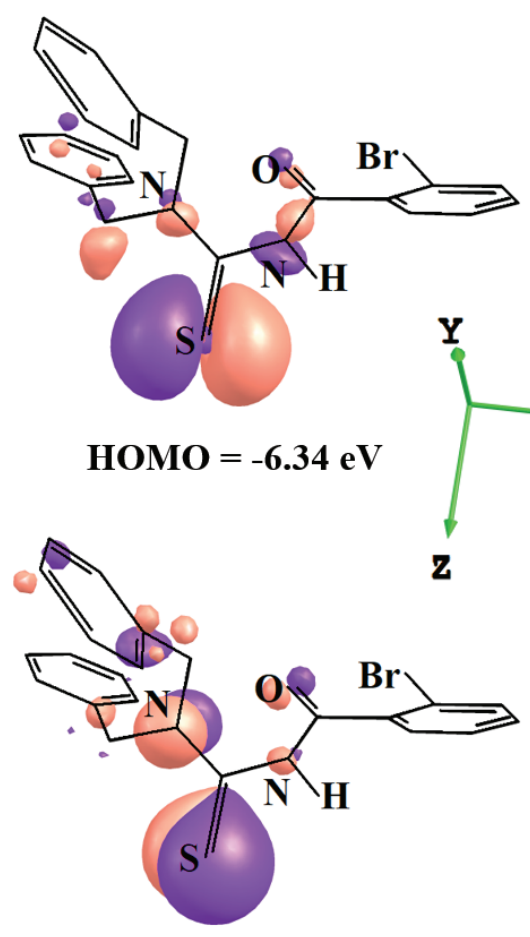

HOMO-1 $=-6.68 \mathrm{eV}$
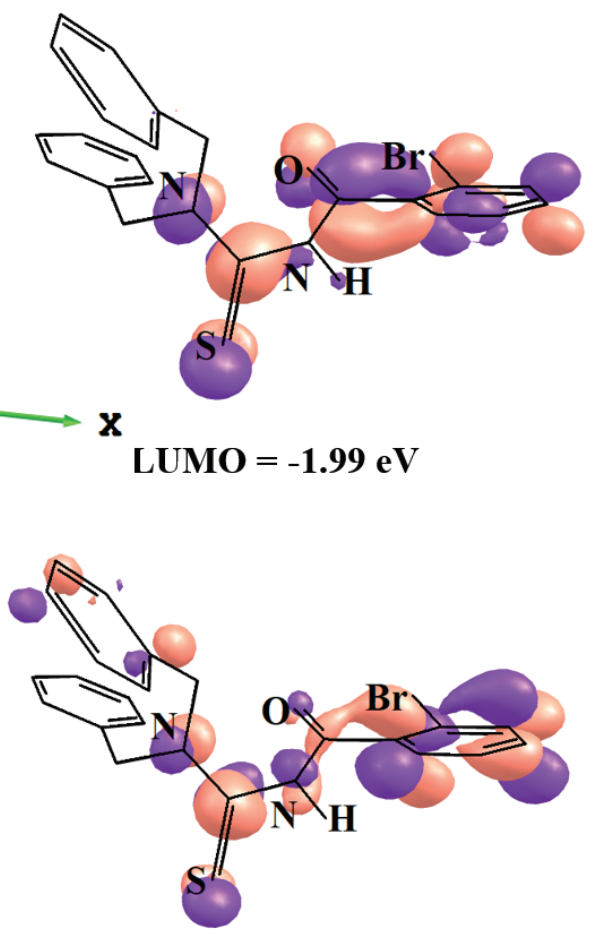

LUMO+1 $=-1.22 \mathrm{eV}$

FIGURE 6. Isosurface plot (contour value $=0.043$ ) of frontier HOMOs and LUMOs for 2BrBT

moment in the 1D helical column parallel to the $C$-axis. The lowest energy involved in the calculated electronic absorption (band I) has not exceeded the $400 \mathrm{~nm}$ threshold and remains transparent throughout the visible and nearinfrared wavelengths $(400-1100 \mathrm{~nm})$. 2BrBT is a promising candidate for use as NLO material and worthy of further experimental efforts.

\section{CONCLUSION}

A benzoylthiourea derivative was successfully developed with deliberate consideration on the non-symmetrical construction of the crystal lattice that was realised by the versatile amide linkage contained within the benzoylthiourea fragment through intermolecular hydrogen bonding. The asymmetrical structural arrangement and charge distribution were enhanced with the presence of a pseudo-six-membered ring created by an intramolecular hydrogen bonding. The frontier molecular orbitals are predominantly found on the benzoylthiourea fragment, where, it is also at the helm of electron delocalisation across the 1D-helical macrostructure. Compound 1,1-dibenzyl-3(2-bromobenzoyl)thiourea has a low transparency cut-off wavelength $(<400 \mathrm{~nm})$ and has no optical absorbance in the visible and near-infrared region, which is ideal for a nonlinear optical material.

\section{ACKNOWLEDGEMENTS}

The authors would like to acknowledge the Ministry of Science \& Technology (MOSTI) and Ministry of Higher
Education (MOHE), Malaysia and Universiti Kebangsaan Malaysia (UKM) for sponsoring this project under FRGS/1/2014/SG01/UKM/02/1, 06-01-02-SF1001 and ERGS/1/2013/TK07/UKM/02/2, UKM/AP/TK-05-2009. Special thanks to Prof. Hideaki Kasai, Prof. Wilson Agerico Diño and Osaka University (Japan) for supporting us with the quantum computational facilities. We are grateful to the School of Chemical Sciences and Food Technology, Faculty of Science and Technology and Fuel Cell Institute (UKM) for their relentless support and provision of experimental facilities.

\section{REFERENCES}

Anbarasi, A., Ravi Kumar, S.M., Sundar, G.J.S., Mosses, M.A., Raj, M.P., Prabhakaran, M., Ravisankar \& Gunaseelan, R. 2017. Investigations on synthesis, growth and physicochemical properties of semi-organic NLO crystal bis(thiourea) ammonium nitrate for nonlinear frequency conversion. Physica B: Condensed Matter 522: 31-38.

Balaji, J., Prabu, S. \& Srinivasan, P. 2016. (E)-N'-(4chlorobenzylidene)-4-methylbenzenesulfonohydrazide (4CBTH)-Synthesis and characterization of organic NLO crystal. Journal of Crystal Growth 452: 189-197.

Becke, A.D. 1993. Density functional thermochemistry III the role of exact exchange. Journal of Chemical Physics 98: 5648-5652.

Becke, A.D. 1988. Density-functional exchange-energy approximation with correct asymptotic behavior. Physical Review A 38(6): 3098-3100.

Bosshard, C., Bösch, M., Liakatas, I., Jager, M. \& Günter, P. 2000. Nonlinear Optical Effects and Materials, edited by Gun, P. Berlin: Springer-Verlag. 
Cossi, M., Rega, N., Scalmani, G. \& Barone, V. 2003. Molecules in solution with the C-PCM solvation model. Journal of Computational Chemistry 24(6): 669-681.

Dalton, L.R., Günter, P., Jazbinsek, M., Kwon, O.P. \& Sullivan, P.A. 2015. Organic Electro-optics and Photonics: Molecules, Polymers and Crystals. Cambridge: Cambridge University Press.

Davidson, E.R. \& Feller, D. 1986. Basis set selection for molecular calculations. Chemical Reviews 86(4): 681-696.

Fui, M.L.W., Hang, N.K., Arifin, K., Minggu, L.J. \& Kassim, M.B. 2016. Photocatalytic degradation of bromothymol blue with Ruthenium(II) bipyridyl complex in aqueous basic solution. AIP Conference Proceedings 1784(II): 1-6.

Fui, M.L.W., Hang, N.K., Minggu, L.J., Umar, A.A. \& Kassim, M.B. 2012. Determination of band energy levels for tungsten nitrosyldithiolene. Sains Malaysiana 41(4): 439-444.

Hassan, I.N., Yamin, B.M. \& Kassim, M.B. 2008. Ethyl 2-(3-benzoyl $\{\backslash\}$ thio $\{\backslash-\}$ ureido)acetate. Acta Crystallographica Section E 64(9): o1727.

Hehre, W.J., Radom, L., Schleyer, P.V.R. \& Pople, J.A. 1986. Ab initio molecular orbital theory. Accounts of Chemical Research 9: 399-406.

Irudaya Jothi, A. \& Alexander, V. 2017. Organic NLO material with H-bonded 1D helical self-assembly: Synthesis, X-ray crystal structure, DFT calculations, SHG measurements and thermal studies of $(5 \mathrm{Z}, 6 \mathrm{E})$-1,10-phenanthroline-5,6-dione dioxime. CrystEngComm. 19(35): 5251-5258.

Jazbinsek, M., Mutter, L. \& Gunter, P. 2008. Photonic applications with the organic nonlinear optical crystal DAST. IEEE Journal of Selected Topics in Quantum Electronics 14(5): 1298-1311.

Lee, C., Yang, W. \& Parr, R. 1988. Development of the ColleSalvetti correlation energy formula into a functional of the electron density. Physical Review B 37(2): 785-789.

Lee, S., Jazbinsek, M., Hauri, C.P. \& Kwon, O. 2016. Recent progress in acentric core structures for highly efficient nonlinear optical crystals, their supramolecular interactions and terahertz applications. CrystEngComm. 18: 7180-7203.

Mark-Lee, W.F., Ng, K.H., Minggu, L.J., Umar, A.A. \& Kassim, M.B. 2013. A molybdenum dithiolene complex as a potential photosensitiser for photoelectrochemical cells. International Journal of Hydrogen Energy 38(22): 9578-9584.

Mark-Lee, W.F., Rusydi, F., Minggu, L.J. \& Kassim, M.B. 2017. Bis(Bipyridyl)-Ru(II)-1-benzoyl-3-(pyridine-2-yl)-1Hpyrazole as potential photosensitiser: Experimental and density functional theory study. Jurnal Teknologi 79(5-3): 117-123.

Miertuš, S., Scrocco, E. \& Tomasi, J. 1981. Electrostatic interaction of a solute with a continuum. A direct utilizaion of Ab initio molecular potentials for the prevision of solvent effects. Chemical Physics 55(1): 117-129.
Nasir, M.F.M., Hassan, I.N., Wan Daud, W.R., Yamin, B.M. \& Kassim, M.B. 2011. 2-Bromo-N-(dibenzylcarbamothioyl)benzamide. Acta Crystallographica Section E: Structure Reports Online E67: o1218.

Ngah, N., Kassim, M.B. \& Yamin, B.M. 2006a. (2S)-1-(Benzoylthiocarbamoyl)pyrrolidine-2-carboxylic acid monohydrate Acta Crystallographica Section E 62(10): o4501-o4502.

Ngah, N., Kassim, M.B. \& Yamin, B.M. 2006b. 2-(3-Benzoylthioureido)propionic acid. Acta Crystallographica Section E 62(1): 0381-0382.

Purusothaman, R., Rajesh, P. \& Ramasamy, P. 2015. Growth and characterization of organic NLO material: Clobetasol propionate. Spectrochimica Acta - Part A: Molecular and Biomolecular Spectroscopy 145: 235-238.

Shahriari, E., Mahmood Mat Yunus, W., Talib, Z.A. \& Saion, E. 2011. Thermal-induced non-linearity of ag nano-fluid prepared using $\gamma$-radiation method. Sains Malaysiana 40(1): 13-15.

Shi, Y., Frattarelli, D., Watanabe, N., Facchetti, A., Cariati, E., Righetto, S., Tordin, E. Zuccaccia, C., Macchioni, A., Wegener, S.L., Stern, C.L., Ratner, M.A. \& Marks, T.J. 2015. Ultra-high-response, multiply twisted electro-optic chromophores: Influence of $\pi$-system elongation and interplanar torsion on hyperpolarizability. Journal of the American Chemical Society 137(39): 12521-12538.

Tan, S.S., Aisha A. Al-abbasi, Tahir, M.I.M. \& Kassim, M.B. 2014. Synthesis, structure and spectroscopic properties of cobalt(III) complexes with 1-benzoyl-(3,3-disubstituted) thiourea. Polyhedron 68: 287-294.

Wun Fui Mark-Lee \& Mohammad B. Kassim*

School of Chemical Sciences and Food Technology

Faculty of Science and Technology

Universiti Kebangsaan Malaysia

43600 UKM Bangi, Selangor Darul Ehsan

Malaysia

Mohd Faizal Md Nasir

Fuel Cell Institute

Universiti Kebangsaan Malaysia

43600 UKM Bangi, Selangor Darul Ehsan

Malaysia

*Corresponding author; email: mb_kassim@ukm.edu.my

Received: 16 September 2017

Accepted: 11 November 2017 
